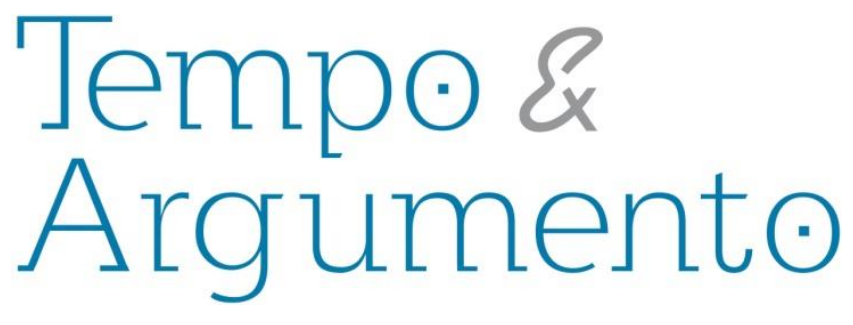

\title{
Micro-história e história da imigração: pensando o problema do equilíbrio e da complexidade
}

\begin{abstract}
Resumo
O presente artigo tem por objetivo mostrar de que maneira a metodologia da micro-história italiana propiciou o desenvolvimento dos estudos ligados aos movimentos migratórios. Inspiradas em tal metodologia, as pesquisas começaram a dar destaque às experiências particulares de deslocamento, indicando para o papel ativo dos indivíduos e das famílias na articulação dos deslocamentos. Os conceitos de cadeias migratórias, redes e estratégias passaram a ser utilizados propiciando, assim, que as explicações que entendiam as transferências como consequência de fatores estruturais econômicos fossem colocadas em novos termos. A busca pelo entendimento do mundo de saída dos camponeses europeus e os recursos acionados pelas famílias quando chegavam à América, bem como as conexões entre os locais de origem e os de chegada, aparecem ainda como pontos que merecem ser aprofundados quando se fala da imigração para regiões de colonização no Brasil. Por tudo isso, indicar-se-á de que modo o método da microhistória pode ainda contribuir significativamente para o desenvolvimento das pesquisas no campo dos deslocamentos humanos.
\end{abstract}

Palavras-chave: Emigração e Imigração. Italianos.

América Latina.

\section{Para citar este artigo:}

VENDRAME, Ines Vendrame. Micro-história e história da imigração: pensando o problema do equilíbrio e da complexidade. Tempo e Argumento, Florianópolis, v. 10, n. 25, p. 267 288, jul./set. 2018.

DOI: $10.5965 / 2175180310252018267$

http://dx.doi.org/10.5965/2175180310252018267 


\title{
Microhistory and history of immigration: thinking about the problem of balance and complexity
}

\begin{abstract}
The present article aims to show how the methodology of Italian microhistory has led to the development of studies related to migratory movements. This methodology started to highlight the particular experiences of displacement, indicating to the active role of individuals and families in the articulation of displacements. The concepts of migration chains, networks and strategies have been used, thus allowing the explanations that understood the transfers as a consequence of structural economic factors to be put in new terms. The quest for an understanding of the world of European peasants leaving the country and the resources that families had when they arrived in America, as well as the connections between places of origin and arrivals, are also points that deserve to be deepened when one speaks of immigration to Regions of colonization in Brazil. For all this, it will be indicated how the method of microhistory can still contribute significantly to the development of research in the field of human displacements.
\end{abstract}

Keywords: Emigration and immigration. Italians. Latin America.

\section{Sobre micro-história}

Na Itália, a partir da década de 70 do século XX, começou a se desenvolver uma metodologia que se tornou conhecida como micro-história. Essa passaria a ter crescente aceitação entre os pesquisadores que, através de uma abordagem etnográfica, buscavam compreender as práticas sociais e culturais das sociedades camponesas. Tal perspectiva de análise surge enquanto reação à crescente insatisfação por parte de alguns pesquisadores frente às análises estruturais e funcionalistas. O desejo de romper com os modelos explicativos demandava novos métodos para abordar amplos fenômenos históricos. 
Assim, através da Revista Quaderni Storici, ${ }^{1}$ tem início uma abertura significativa para a interdisciplinaridade nos estudos históricos. No referido periódico é aberto um espaço para serem publicados os estudos que irão propiciar uma renovação historiográfica, fazendo parte da série definida como Microstorie. Esta se apresentava através de um renovado interesse pela história social em diálogo com a etno-história, a economia e a antropologia. Os métodos e problemas trazidos de outras ciências sociais ajudavam a ampliar as discussões sobre o tema da família, comunidade e universo camponês, tendo como preferência o micro, o local e o individual como ponto de partida para diferentes estudos. Assim, reunidos em torno da Revista Quarderni Storici, historiadores como Edoardo Grendi, Giovanni Levi, Carlo Ginzburg e Carlo Poni passaram a divulgar suas pesquisas. ${ }^{2}$

Variando entre uma abordagem mais voltada para questões da história social e econômica, enquanto outra direcionada mais para o campo da história cultural, o que aproximava os referidos estudiosos era a comum insatisfação frente aos grandes modelos explicativos de análises. Tudo isso somado ao interesse pela reconstituição das experiências individuais e familiares dos camponeses e pessoas comuns, método esse considerado necessário para apreender as compreensões, explicações, racionalidades e comportamentos próprios de um grupo e de uma época (LIMA, 2006; MARQUIEGUI, 2016). Edoardo Grendi (1977; 1981) e Giovanni Levi (1985; 2000), interessados na proposição de uma nova história social preocupada com as percepções e articulações específicas da população do campo na Itália do Antigo Regime, passaram a ressaltar a importância de se analisar as redes sociais e vínculos interpessoais. O interesse de ambos voltou-se, portanto, para a compreensão das dinâmicas relacionais e lógicas que orientavam os comportamentos individuais e coletivos, bem como para o funcionamento de certas estruturas socais.

Sendo assim, umas das principais contribuições dos referidos historiadores foi de perceber o papel ativo das populações que habitavam no campo frente às pressões do

\footnotetext{
${ }^{1}$ Sobre o nascimento da revista Quaderni Storici e as discussões em torno dela na década de 70 do século XX na Itália, ver: LIMA, 2006.

${ }^{2}$ A revista Quaderni Storici, desde o início dos anos 80, foi o espaço de debates entre os historiadores italianos fundadores da Micro-História. Sobre esse assunto, consultar: LIMA, 2006.
} 
Estado Absolutista e do sistema econômico, analisando as estratégias e recursos acionados pelas famílias nas comunidades. A relação entre essas duas esferas - família e comunidade - e a sociedade mais ampla eram apontadas como fundamentais para o entendimento das mudanças ocorridas no universo rural do período pré-industrial. Edorado Grendi (1981; 1993; 1996) deu ênfase para a esfera local e abordagens etnográficas, destacando-se como um grande empirista, uma vez que considerava a história estritamente ancorada na linguagem da fonte primária. ${ }^{3}$

Nesse sentido, também conferindo importância para abordagens reduzidas, mas não restritas a temas locais, o historiador Carlo Ginzburg passou a utilizar em suas pesquisas o método indiciário e onomástico. Os indícios e sinais pouco frequentes na documentação, bem como a atenção aos documentos excepcionais, passaram a ser destacados como vestígios de problemas de pesquisas mais amplos. Assim, trabalhando com fontes inquisitoriais dos séculos XVI e XVII, Ginzburg (1988) analisou aspectos da cultura agrária daqueles que caíam nas malhas da Inquisição, interesse esse considerado marginal no ambiente acadêmico da década de 50 e 60 do século XX. Ao buscar entender o sentido da palavra benandanti ${ }^{4}$, localizada nas fontes primárias, o referido autor adentrou no universo das crenças e cultos próprios de uma cultura camponesa. Orientando-se pela perspectiva do paradigma indiciário ${ }^{5}$, os detalhes e os indícios encontrados na documentação foram percebidos como sinais que poderiam ser reveladores de práticas sociais e culturais da população rural que eram de longa data e completamente desconhecidos pela cultura erudita da Igreja católica. Desse modo, os

\footnotetext{
${ }^{3}$ Uma das principais características dos trabalhos de Eduardo Grendi era a associação entre a pesquisa história empírica e a discussão teórica. Aproximando-se dos debates realizados no campo da antropologia econômica, seus estudos sobre história do trabalhismo e vida associativa das classes subalternas nas cidades foram sendo influenciados pela perspectiva "a partir de baixo". A aproximação com outros pesquisadores - Giovanni Levi e Carlo Poni - se deu pelo interesse em analisar as comunidades e o mundo pré-industrial à luz de problemas conectados: relações entre centro/periferia no contexto de constituição do Estado Moderno, significados e formas de organização social, demográficas e econômica, protagonismo local e comunidades (LIMA, 2006).

${ }^{4} \mathrm{O}$ termo benandanti era a denominação para aqueles indivíduos que haviam nascido envoltos pela película amniótica, motivo pelo qual deviam ter poderes sobrenaturais, cabendo a eles a tarefa de proteger os povoados e as plantações. Esta crença era muito difundida nos séculos XVI e XVII entre as populações camponesas da região do Friul, nordeste da península itálica. Através do processo movido pela Santa Inquisição, os benandanti foram considerados feiticeiros, conforme constatou Carlo Ginzburg (1988) no livro "Os andarilhos do bem: feitiçaria e cultos agrários nos séculos XVI e XVII".

${ }^{5}$ Sobre o método ou paradigma indiciário defendido e utilizado por Carlo Ginzburg, ver: GINZBURG, 1987; 2007; 2011.
} 
pequenos vestígios eram tomados como aspectos reveladores ou como a chave de leitura para se analisar determinados comportamentos.

Já no livro intitulado Queijo e os vermes, Carlo Ginzburg (1987), utilizando-se do "método onomástico", 6 analisou a trajetória de Domenico Scandela, conhecido como Menochio. Este, um moleiro que viveu na região do Friul no século XVI, foi preso pela Santa Inquisição por possuir ideias “extravagantes” a respeito do surgimento do universo e que iam contra os dogmas da Igreja católica. Através das explicações conferidas pelo personagem estudado, Ginzburg procurou compreender aspectos como a circularidade entre a baixa e a alta cultura, no contexto da contrarreforma e da difusão da imprensa.

As contribuições dos pais fundadores da micro-história italiana ${ }^{7}$ influenciaram a produção historiográfica na Europa e, em seguida, os estudos históricos na América Latina. Em relação ao Brasil, tal influência pode ser percebida até o presente momento, uma vez que as contribuições da referida corrente historiográfica continuam a inspirar pesquisas nos mais diversos campos temáticos da história. As sugestões teóricas e metodológicas dos dois dos principais expoentes da microanálise, Carlo Ginzburg e Giovanni Levi, seguem inspirando muitas pesquisas desenvolvidas nos principais centros acadêmicos nacionais. Em relação às ideias de Levi, esse destaca a opção por pensar a história social conectada a diferentes aspectos, sejam eles sociais, econômicos, políticos e culturais, independentemente do tema da pesquisa. Para tanto, muitos ainda utilizam o livro Herança Imaterial (LEVI, 2000) para desenvolverem seus trabalhos.

Nesse sentido, a história de um "tosco" padre de aldeia é escolhida como objeto da narrativa e também como justificativa para a reconstituição do ambiente social e cultural de uma "cidadezinha comum”. São, portanto, “as estratégias cotidianas de um fragmento do mundo camponês" que propuseram temas e problemas gerais, pois uma visão mais ampla e de fora não os tornaria visíveis. Foi o cotidiano e as reações de pessoas comuns que Giovanni Levi (2000, p. 43-47) procurou mostrar em sua pesquisa, aliás, um

\footnotetext{
${ }^{6} \mathrm{O}$ método onomástico é um procedimento de pesquisa que se inspirava na demografia histórica, estando ligada à documentação serial que poderia ser paroquial ou notarial (GINZBURG; PONI, 1989b, p. 174-175).

7 Os considerados pais fundadores da micro-história italiana são: Edoardo Grendi, Giovanni Levi, Carlo Ginzburg e Carlo Poni. Sobre a trajetória historiográfica dos mencionados historiadores, seus debates em torno da Revista Quaderni Storici e suas contribuições teóricas e metodológicas para a micro-história italiana, Henrique Espada Lima (2006) realiza investigação minuciosa e rica em informações.
} 
universo social que não pode ser visto como imóvel, defensivo e incapaz de se articular e desenvolver iniciativas autônomas frente às transformações gerais da época. Solidariedades, tensões e acordos atravessam as relações no interior da comunidade camponesa que vivia um processo de divisões e desarmonias. Além disso, também constatou que uma "homogeneidade cultural" se apresentava em momentos de conflitos e contradições, sendo acompanhada pela formação contínua de equilíbrios e harmonias relacionais, essas sujeitas constantemente a "novas rupturas". Foram essas constatações que tornaram o estudo válido para a compreensão dos comportamentos e racionalidades em sociedades localizadas em tempos e espaços diferentes.

Tendo em vista as ideias apresentadas até então a respeito dos expoentes da micro-história italiana e suas principais contribuições, pode-se, então, perceber que não existe uma definição única da referida metodologia, sendo ela uma prática historiográfica baseada na redução da escala de observação. Entendo que as sugestões metodológicas apresentadas acima vêm contribuindo para a renovação dos estudos sobre determinadas temáticas, especialmente o tema das migrações transoceânicas e das comunidades fundadas no território brasileiro pelos imigrantes europeus nas últimas décadas do século XIX. Percebe-se um intenso diálogo com a metodologia da micro-história, o que está contribuindo para repensar as estratégias familiares de sobrevivência e deslocamento no território da península itálica do Antigo Regime. Logo, o presente trabalho busca fazer uma análise sobre a influência do método da microstoria italiana nos estudos ligados aos movimentos migratórios para a América. Na sequência, indica de que forma essa aproximação pode continuar a propiciar a renovação das pesquisas ligadas ao tema das e/imigrações e sobre as comunidades fundadas pelos imigrantes no Brasil.

\section{Cadeias migratórias}

Os estudos sobre o movimento migratório europeu para a América Meridional, com especial atenção para a Argentina, tiveram grande desenvolvimento a partir da década de 80 do século XX. A utilização do conceito de "cadeias migratórias" serviu para que entendêssemos como os camponeses se inteiravam das oportunidades existentes na 
América, em questões como o transporte, empregos e outros auxílios. As cadeias migratórias eram relações que os italianos possuíam com aqueles que já estavam instalados nos locais de destino na América. Nesse sentido, as redes e contatos que uniam os dois lados do Atlântico auxiliavam a organizar as partidas e a escolher os destinos, determinando, nas terras distantes, um padrão de acomodação e ocupação dos recém-chegados.

Cadeia migratória foi um conceito inicialmente utilizado para entender o movimento de imigrantes para a América do Norte. Essa definição, entendida como bastante ampla, incluía aqueles que articulavam as transferências baseados nas informações passadas por amigos e parentes que já estavam nos Estados Unidos (MACDONALD, MACDONALD, 1964; DEVOTO, 1988). ${ }^{8}$ Esses historiadores estudavam essas dinâmicas de deslocamento como resposta à crise das explicações macroestruturais sociais e econômicas.

Com a aproximação de abordagens antropológicas, os novos estudos sobre a imigração passaram a se preocupar em entender os deslocamentos de grupos de indivíduos e suas dinâmicas, preparando, assim, o terreno para o desenvolvimento de pesquisas que utilizavam os métodos da micro-história italiana. O uso do conceito de cadeias migratórias possibilitou pensar os imigrantes como sujeitos ativos, capazes de formular estratégias de sobrevivência e adaptação visando concretizar projetos individuais e familiares em contextos de mudanças políticas e econômicas. Logo, os locais de partida e os de destino passaram a ser alvo de estudos daqueles que buscavam entender o fenômeno de grandes proporções como o das migrações (DEVOTO, 1988; 1994). As migrações transoceânicas, que caracterizaram a Itália nas últimas décadas do século XIX, foram interpretadas dentro de uma "cultura da mobilidade" muito presente no território da península itálica desde o Antigo Regime, propiciando, desse modo, o

\footnotetext{
${ }^{8} \mathrm{O}$ primeiro estudo a detalhar o funcionamento das cadeias migratórias e a difundir sua utilização entre pesquisadores que pensavam as mobilidades da Europa para a Austrália e os Estados Unidos foi o de John S. MacDonald e Leatrice MacDonald (1964), tendo desenvolvido suas pesquisas na década de 60 do século XX. Posteriormente, outros pesquisadores que analisaram o fenômeno migratório para a América trabalharam com o conceito de cadeia migratória e suas diferentes abordagens: DEVOTO, 1988; BAILY, 1988, p. 125-135; GANDOLFO, 1988, p. 160-177; RAMELLA, 1991, 1999; CORTI, 1990.
} 
questionamento do modelo estrutural de atração e expulsão, o push-pull ${ }^{9}$. As explicações que conferiam força apenas aos fatores econômicos de expulsão da população camponesa frente ao avanço do capitalismo no campo passaram, portanto, a sofrer críticas, na medida em que outros fatores, esses mais ligados às lógicas e estratégias de reprodução das famílias, começaram a ganhar destaque.

Assim, na busca pela compreensão das dinâmicas migratórias, a utilização de novas fontes e técnicas permitiu aprofundar o entendimento do funcionamento das cadeias e redes, tentando apreender suas racionalidades de funcionamento. Listas de desembarque, registros paroquiais e cartoriais e a documentação das associações de mútuo-socorro começaram a ser utilizados em análises quantitativas e qualitativas que buscavam apreender os mecanismos de inserção social nos espaços de acomodação no sul da América. ${ }^{10}$ Nesse sentido, o conceito de cadeia foi considerado uma das mais frutíferas técnicas para lançar luz sobre a dinâmica dos movimentos migratórios, sendo seguido pela compreensão de outros mecanismos, como das redes interpessoais. Ambas as ideias possibilitaram a ligação entre os lugares de origem com os de destino, conectando os dois lados do Atlântico, aspecto esse muito importante para perceber a participação individual e coletiva nos deslocamentos, as expectativas familiares e comunitárias e os aspectos sociais e culturais transplantados da pátria mãe para os novos locais de instalação. Além disso, também foram indispensáveis para pensar, especialmente no caso da imigração italiana para o Novo Mundo, as formas de inserção e construção do patrimônio material e imaterial na sociedade de adoção (STURINO, 1988; CORTI, 1990).

As cadeias migratórias ocorriam através da ativação de relações sociais primárias que garantiam a transferência de pessoas de um mesmo local de origem para outro de destino, centrando-se na conexão entre duas comunidades. Porém, as redes e os vínculos que alimentavam os fluxos migratórios necessariamente não ficavam restritos apenas aos

\footnotetext{
9 Sobre a utilização do conceito de cadeias e a mudança de perspectiva que suplantou os modelos explicativos do push/pull nos estudos migratórios para a América do Norte e do Sul, ver: DEVOTO, 1988, BAILY, 1988; RAMELLA, 1995: 2001; STURINO, 1988; MARQUIEGUI, 1995,

${ }^{10}$ Sobre a utilização de novas fontes nos estudos que analisavam mobilidade espacial, redes e inserção social dos imigrantes europeus na Argentina nas últimas décadas do século XIX e início do XX, ver: OTERO, 1995; MARQUIEGUI, 1995; DA ORDEN, 1995.
} 
limites territoriais de uma determinada aldeia, eles podiam ser amplos, envolvendo comunidades limítrofes ou mais distantes. As tramas de contato através das quais os deslocamentos eram organizados transcendiam os espaços geográficos, uma vez que os laços parentais e de amizade entre as pessoas funcionavam como os principais constituidores dos canais de conexões entre diferentes locais (VENDRAME, 2016a). ${ }^{11}$ Os matrimônios, as atividades agrícolas e as migrações eram responsáveis por construir uma teia de relações simbólicas e recíprocas entre as famílias e indivíduos que ultrapassam os limites fronteiriços das pequenas aldeias. Os laços extensos entre os habitantes de áreas limítrofes, dentro de uma mesma província, foram reforçados com os deslocamentos, facilitando as transferências e as estratégias de acomodação no além-mar, pois estavam assentadas sob um intrincado sistema de direitos e obrigações mútuas entre vizinhos, parentes e amigos.

Nesse sentido, a coesão entre as famílias extensas foi um aspecto facilitador da emigração, funcionando graças à difusão das informações através dos canais interpessoais. A existência efetiva de um espaço social construído por uma rede, que conectava as comunas, permitiu a diversificação da cadeia migratória, conforme observou Franc Sturino (1988) ao analisar os deslocamentos na zona de Rende, na Itália.

A preocupação com a questão da escala nos estudos migratórios significou uma importante renovação, o que, somando-se aos conceitos de cadeia e de redes, possibilitou entender serem múltiplas as motivações dos deslocamentos. Já há algumas décadas, essa tem sido a metodologia adotada por muitos estudiosos: acompanhar as escolhas, expectativas e estratégias individuais ou de grupos desde a pátria de origem até os locais de instalação. A opção por reduzir a lente de observação focando as experiências e contextos específicos têm sugerido novos questionamentos sobre a pluralidade das motivações que faziam as pessoas abandonarem definitivamente a pátria, bem como revelado a heterogeneidade dos mecanismos acionados e percepções dos

\footnotetext{
${ }^{11}$ Franco Ramella (2001) aponta que dentro de espaços geográficos mais amplos, os camponeses se organizavam através da família extensa, sendo as escolhas de cada um integradas às decisões do amplo grupo parental. Logo, as estratégias das famílias e indivíduos estavam diretamente relacionadas aos recursos relacionais que podiam acionar, garantindo a eficiência dos projetos migratórios de transferência da parentela extensa.
} 
sujeitos que compuseram o movimento migratório para América nas últimas décadas do século XIX e início do XX.

A análise das cadeias como um movimento entre um lugar de origem e outro de destino, segundo alguns autores, deve considerar as múltiplas dinâmicas e locais envolvidos nesse processo amplo e complexo (Zucchi apud DEVOTO, 1988, p. 106). A busca pela complexidade se contraporia, portanto, à imagem idílica marcada pela ideia de coesão e solidariedade paesana e parental conferida ao fenômeno migratório e à vida nas comunidades étnicas fundadas na América. Enquanto uma estratégia de mobilidade, que se soma a outras identificadas nas pesquisas sobre os deslocamentos transatlânticos, o estudo das cadeias migratórias só foram possíveis, segundo Fernando Devoto (1988, p. 109), graças à inclusão de novas fontes, como os registros dos sócios das sociedades de mútuo-socorro.

Pensando as implicações que comportam o uso da noção de cadeia para a compreensão das correntes migratórias para o território argentino, destacam-se os trabalhos de Samuel Baily (1988) e de Romolo Gandolfo (1988). Através de análises de grupos específicos, o primeiro realizou um estudo articulado do funcionamento das redes sociais informais na conexão entre a sociedade de origem e a receptora. Foram identificadas diferentes tipos de cadeias: essas podiam passar pela constituição de mecanismos de assistência interpessoal e espontânea de comunicação e auxílio, ou ainda, pela ajuda de intermediários externos às redes migratórias. Para o estudo das redes sociais e estratégias de deslocamento, além das listas de passageiros, de distribuição dos lotes de terras, registros de naturalização, fontes eclesiásticas e outras, os documentos pessoais - como diários e cartas trocadas entre os sujeitos que se encontravam nos dois lados do Atlântico -, se apresentam como fontes privilegiadas. ${ }^{12}$

As pesquisas de Fernando Devoto (1988:1994), Samuel Baily (1988) e Romolo Gandolfo (1988) auxiliaram no entendimento e refinamento da concepção de cadeia migratória para o caso da Argentina. Todos eles compreenderam os diferentes tipos de

\footnotetext{
12 Sobre a utilização das cartas para a compreensão da imigração italiana para a América nas últimas décadas do século XIX e início do XX ver: FRANZINA, 1979; BAILY: RAMELLA, 1988; GIBELLI, 1989; CIAFARDO, 1991; RAMELLA, 2001; CROCI, 2010; VENDRAME, 2016a; $2017 a$.
} 
cadeias migratórias e da ligação entre os locais de origem e de chegada, percebendo que os imigrantes queriam tirar vantagens no campo material tentando formar uma "elite" na sociedade receptora. As famílias que imigraram através das cadeias mantinham os apoios, esses iniciados ainda na pátria de origem, bem como buscavam reforçar os vínculos de identificação e coesão interna de grupo, constituindo, através dessas dinâmicas, certas hierarquias sociais (GANDOLFO, 1988).

Portanto, o peso das relações interpessoais na compreensão do movimento migratório não poderia mais ser deixado de lado, passando as famílias e indivíduos a serem vistos como ativos no processo de transferência e constituição de novas comunidades na América meridional. Além do acesso a vantagens protetivas e solidariedade étnica, mantida através do reforço dos vínculos primários e consequência de uma imigração em cadeia, a necessidade de fortalecimento das afinidades nos locais de destino funcionava como um mecanismo que controlava os conflitos sociais impossíveis de serem evitados frentes às tensões que permeavam o cotidiano.

Como visto anteriormente, com a revisão da explicação do push/pull, que durante muito tempo dominou os estudos migratórios, passou-se para abordagens que valorizavam os contatos interpessoais e recursos relacionais, servindo para obter informações seguras junto àqueles que já se encontravam no além-mar e garantir uma transferência segura, além de vantagens como terra e trabalho nos locais de instalação. Se o uso de novos conceitos e métodos provocou a renovação dos estudos sobre os movimentos migratórios, tanto para os Estados Unidos como para a América do Sul ${ }^{13}$, no Brasil, porém, essa discussão tardou para acontecer. Apenas recentemente, através do uso da metodologia ligada à micro-história, percebe-se o surgimento de pesquisas voltadas para o entendimento das estratégias familiares de deslocamento e o papel das redes sociais na imigração italiana para o território brasileiro. Seguir as escolhas das famílias e grupos de emigrantes desde a aldeia de origem, buscando entender as motivações que os levaram a emigrar, tem-se mostrado uma das perspectivas mais fecundas (CONSTANTINO, 2008; PEREIRA, 2008, CARVALHO, 2009; VENDRAME, 2016a). O

\footnotetext{
${ }^{13}$ A utilização dos conceitos de cadeias e redes migratórias nos estudos voltados à imigração europeia na Argentina foram amplamente discutidas nos capítulos que constituem a coletânea intitulada Inmigracón $y$ redes sociales en la Argentina Moderna (BJERG; OTERO, 1995).
} 
emprego do conceito de cadeia e rede como instrumento de análise útil para o desenvolvimento das pesquisas no campo da imigração italiana, seguindo tardiamente o que já há muitas décadas ocorreu na Argentina, começou a dar os primeiros passos no Brasil através do uso intensivo de fontes documentais de origens diversas, como cartas, diários, memórias, listas de distribuição dos lotes de terra e registros paroquiais.

\section{Micro-história e História da Imigração}

Nesta parte do artigo discutirei de que modo a metodologia da micro-história pode continuar contribuindo para o avanço dos estudos ligados à imigração europeia do final do século XIX e início do XX para o Brasil. Partirei das ideias de Giovanni Levi (2015; 2016a) presente em dois ensaios: o primeiro intitulado “Micro-história e História da Imigração", e o segundo, "30 anos depois: repensando a Micro-história”. ${ }^{14}$

Pensando na questão dos deslocamentos, Levi aponta como imprescindível o estudo dos locais de partida dos camponeses europeus no período da "Grande Emigração" (1875-1914). Mais do que isso, orienta que devemos estudar o mundo relacional dos dois lugares - o de origem e o de chegada - buscando perceber em que momento do ciclo de vida das famílias ocorria a emigração, quem, como e em quais condições os sujeitos se utilizavam da estratégia da mobilidade para garantir a reprodução e sobrevivência do grupo. Independentemente de partirem sozinhos, acompanhados da família ou na companhia de um agregado de conhecidos, a existência de redes interpessoais, constituídas por "laços de sangue" e vínculos simbólicos, propiciou a formação de uma ponte entre o local de partida e o de destino, garantindo, desse modo, a constituição de novas comunidades no além-mar que guardavam características das de origem.

\footnotetext{
${ }^{14}$ Tanto o mencionado artigo, quanto o intitulado "História Total versus Global History: a historiografia antes e depois da queda do Muro de Berlim", ambos de autoria de Giovanni Levi, fazem parte do livro Ensaios de micro-historia, trajetória e imigração (VENDRAME, KARSBURG, MOREIRA, 2016b). Nos dois artigos, Levi ressalta que a redução de escala é um dos pontos que caracteriza a microstoria, devendo extrair dos problemas sociais analisados perguntas gerais de pesquisa. Entende que a história é uma "ciência das perguntas gerais e das respostas locais por meio de uma observação intensa de um problema, um lugar, um acontecimento, uma instituição", devendo ela estabelecer diálogo com antropologia, economia, psicologia. Por tudo isso, defende as aproximaçóes entre o projeto da microstoria e o da Global History, em que a preocupação com os problemas de pesquisas deve permitir estabelecer comparações que não se restrinjam ao local (LEVI, 2016b, p. 82).
} 
O estudo das motivações que provocaram os deslocamentos é apontado como fundamental para compreender as dinâmicas e racionalidades internas de fenômenos amplos como o das migrações. Especialmente porque faz pensar numa questão muito importante dentro do universo familiar camponês, que é o problema do equilíbrio, aspecto esse não estudado segundo Levi (2015). Geralmente, se aborda aquilo que "ocorreu sem pensar naquilo que não ocorreu", analisando-se as escolhas e o contexto dos imigrantes nas terras brasileiras e a organização das novas comunidades, sem buscar entender o que aconteceu com aqueles que não partiram, ou seja, os que permaneceram na pátria de origem.

Reconstruir o mundo relacional das duas pontas, comunidade de origem e de destino, procurando unir as partes de um mesmo processo e buscando entender as conexões existentes, explicará muito mais sobre a emigração e os atores desse fenômeno. Tanto os deslocamentos de curta distância, como os de longa distância, aqui no caso os transatlânticos, não podem ser entendidos sem levar em conta a questão da estrutura familiar. Através do estudo das características internas dos grupos familiares é possível entender as escolhas e estratégias de mobilidade espacial, pois são campos que estão intimamente relacionados.

A imigração acontecia quando da presença de um equilíbrio entre a demanda de consumo e a quantidade de trabalhadores, já que a família poderia investir na viagem de alguém sem prejudicar a organização e sobrevivência do grupo. Essa questão permite entender as escolhas no arranjo dos deslocamentos em etapas, até a união de todo um agregado familiar em terras distantes. De acordo com Giovanni Levi (2015, p. 250-51), as famílias camponesas apoiavam as migrações individuais quando a relação entre consumo e trabalho era favorável, pois, nesse momento, podiam suportar o aumento de consumidores sem chegar a um ponto crítico, ou seja, sem que representassem graves desequilíbrios entre força de trabalho, demandas alimentares e outras despesas ligadas à reprodução do grupo.

Com a utilização da metodologia da micro-história nos estudos migratórios começou-se a dar importância para o mundo de partida dos emigrantes e a estrutura familiar das unidades de produção camponesa. Logo, a redução da escala de observação 
passou a evidenciar racionalidades e estratégias familiares, propiciando, assim, lançar questionamentos sobre as motivações, diferenças internas e complexidades de fenômenos amplos como o das migrações (LEVI, 1985; LEVI; RAMELLA, 1989). O olhar mais circunscrito a um lugar, um indivíduo ou grupo permitiu e permitirá lançar novos problemas sobre o tema, algo que não seria possível de ser analisado se não fosse utilizada a perspectiva micro como ponto de partida.

Não é o pequeno e o diferente que importam na pesquisa, mas o quanto esta escala de análise propicia na elaboração de questionamentos sobre distintos aspectos que não seria possível de serem vistos por outro ângulo de observação. Segundo Giovanni Levi (2016a, p. 23), não é "necessariamente a história dos excluídos, dos pequenos, dos que estão nas margens ou além delas". Antes disso, ela se propõe a reconstruir momentos, analisar experiências individuais e situações com olhar crítico, procurando apreender a complexidade dos contextos nos quais os indivíduos agem. Longe de “celebrar a singularidade”, a grande questão é a relação entre o particular, o subjetivo e o geral, especialmente o que pode ser alcançado através da conexão entre essas esferas. Um dos grandes objetivos ao se utilizar o método da micro-história, na visão de Levi (2016a), é o de reconstruir a complexidade nas análises históricas. No caso dos estudos migratórios, isto seria o de pensar as diferentes motivações que impulsionaram os camponeses a abandonar a pátria de origem para se fixar na América e recuperar o peso e a cor das escolhas individuais e familiares dentro de um universo de possibilidades variadas. Assim, frente a um fenômeno geral como o das migrações transoceânicas, um dos objetivos seria o de buscar compreender as diferentes escolhas utilizadas pelos indivíduos, buscando entender os limites da atuação, as lógicas e estratégias como pontos de partida para a proposição de problemas de pesquisas mais amplos.

Da mesma forma que as situações estudadas não devem ser vistas de forma isolada, não são as diferentes respostas que devem ser generalizadas, mas, sim, as perguntas que cada circunstância sugere. Para Giovanni Levi (2015, p. 249), o local não é o ponto de chegada, mas o de partida, reforçando que o "nosso papel é o de colocar em evidência as diferenças" e o de comparar situações para encontrar as oposições, 
dissemelhanças e a heterogeneidade, não eliminando ou escondendo a realidade divergente, conflitante e complexa. Logo, "a micro-história parte considerando as incongruências do real e a parcialidade do conhecimento", procurando através do método ampliar o conhecimento sobre os contextos, bem como alertar para as simplificações e parcialidades dos documentos (LEVI, 2016a, p. 29). Por tudo o que foi exposto, acredito que a metodologia aqui descrita tem muito a oferecer para o avanço dos estudos ligados ao tema da imigração transatlântica e da pluralidade das dinâmicas migratórias.

Outro ponto importante, para além da questão da complexidade, é o “problema do equilíbrio", conforme foi ressaltado anteriormente. Assim, tomando a sugestão de Giovanni Levi de que é necessário analisar a questão do equilíbrio na história da imigração, Ana Silvia Volpi Scott (2016) estudou a trajetória individual e familiar de emigrantes portugueses que, no século XIX, partiram para o Brasil conectando, através de tais experiências, a região de Lousã (Portugal) com a Nova Lousã, localizada no interior de São Paulo. Ao fazer isso, a autora colocou em evidência a questão das diferentes estratégias utilizadas pelos indivíduos e famílias para garantir um equilíbrio necessário para propiciar a reprodução biológica e social. Independentemente do grupo étnico, entendo que estudos como o de Scott devem servir para estabelecermos comparações, pensarmos em novos métodos e avançarmos em nosso conhecimento sobre as estratégias de sobrevivência, reprodução e mobilidades social e geográfica.

As condições e os modos como partiram os indivíduos, se sozinhos, na companhia dos familiares ou conhecidos, está intensamente ligada à estrutura familiar, à relação entre consumo e trabalho e à articulação da uma rede relacional ativa antes, durante e depois dos deslocamentos. Nesse sentido, a questão do equilíbrio deve ser pensada como fator importante ao se analisar as escolhas concernentes à imigração transoceânica, utilizada também para lançar questionamentos a fim de alargar nosso olhar para aquilo que nem sempre aparece com evidência na documentação. As fontes documentais servem para entender os comportamentos dos sujeitos estudados que resultam de momentos específicos, "situações de decisão e ação", ocupando apenas uma pequena parte do cotidiano, já que não demostram os períodos de indecisões, incertezas, 
esperanças e outros sentimentos que não são documentados. Somando-se a essas lacunas, Giovanni Levi (2015, p. 249) afirma que "os documentos são por definição mentirosos" e "socialmente determinados", pois "os ricos produzem mais documentos que os pobres, os homens mais que as mulheres, os brancos mais que os indígenas". Assim, por apresentarem fragmentos distorcidos do passado, dados parciais e mentirosos, uma das tarefas do historiador seria a de buscar garantir certo equilíbrio nas análises históricas, procurando trazer aqueles sujeitos e situações que não surgem com tanta frequência ou que aparecem como marginais nas fontes. Para além de apenas estudar os que deixaram mais documentos, nosso papel enquanto historiadores é o de “criar equilíbrio, colocando todos como participantes [dentro] da história”; por conta disso, devemos ser inimigos dos documentos, apesar de serem esses necessários para a realização do nosso trabalho.

Um dos objetivos do presente artigo foi o de mostrar de que maneira a metodologia da micro-história, a partir de 1970, ajudou a repensar o desenvolvimento dos estudos ligados aos movimentos migratórios italianos para os Estados Unidos, Argentina e Brasil. A análise de experiências particulares - individuais e coletivas -, a utilização dos conceitos de cadeia e redes para o entendimento dos deslocamentos para a América ofereceram novos entendimentos que colocaram em outros parâmetros os modelos explicativos que entendiam as migrações como consequências de movimentos macroestruturais. Com uma abordagem micro, utilizando do método da redução da escala de observação, foi possível perceber as migrações em suas variáveis sociais, econômicas e políticas, certamente decorrentes do avanço do capitalismo no campo e do processo de modificações das relações de trabalho. Porém, transformou os imigrantes em agentes ativos, que assumiram um papel central nos deslocamentos transatlânticos.

Como apontei no presente trabalho, já há algum tempo que as sugestões teóricas e metodológicas da micro-história vêem influenciando o desenvolvimento das pesquisas no campo das migrações. Apesar disso, segundo afirmações recentes de Giovanni Levi (2015), o referido método muito ainda poderá contribuir para a contínua renovação da 
história das mobilidades. Dentre os assuntos que ainda merecem atenção, destacam-se o mundo de saída dos camponeses, as estratégias acionadas pelas famílias e as conexões com as comunidades fundadas no além-mar. Considera-se importante a inclusão desses dois pontos nas análises das racionalidades, comportamentos e dinâmicas sociais das famílias camponesas. Especialmente, porque permitem ampliar o conhecimento sobre as motivações, perspectivas, anseios e trajetórias dos sujeitos que participaram de alguma forma dos deslocamentos, seja partindo para a América ou ficando na aldeia de origem para que outros pudessem partir. Os que ficaram, pouco ou nada aparecem na história da e/imigração.

Ao cruzarmos as opiniões singulares, discordantes ou não, e as escolhas diferentes sobre um mesmo processo, é possível apreender de forma complexa fenômenos e contextos. Nas comunidades fundadas pelos imigrantes italianos no sul do Brasil, o discurso da pobreza e da força dos imigrantes, bem como da coesão e harmonia vivida nos núcleos coloniais, escondem uma realidade intricada de interesses e expectativas, bem como de tensões, divisões e constante conflitos. ${ }^{15}$ São esses cenários perpassados por opiniões discordantes, por oposições e comportamentos conflitantes, mas também marcados por apoios, uniões e solidariedades, que se busca apreender quando o assunto é estudar a imigração e as comunidades fundadas pelos camponeses italianos no Brasil Meridional.

\footnotetext{
${ }^{15}$ Partindo de experiências específicas de imigrantes italianos como fio condutor na pesquisa, no livro 0 poder na Aldeia, buscou-se reconstruir a realidade complexa, permeada por comportamentos e ideias diferentes vividas nos núcleos de colonização italiana do Rio Grande do Sul. Para saber mais sobre esse estudo, ver: VENDRAME, 2016a.
} 


\section{Referências}

BAILY, Samuel; RAMELLA, Franco. One family, two worlds: an italian family's correspondence across the atlantic, 1901-1922. New Brunswick: Rutgers University Press.1988.

BAILY, Samuel L. Cadenas migratórias de italianos a la Argentina: algunos comentarios. Studios migratórios, v.3, n.8, p. 125-135, 1988.

BJERG, M.; OTERO, H. (Comp.). Inmigracón y redes sociales en la Argentina Moderna. Tandil: CEMLA-IEHS, 1995.

CARVALHO, Rosane Aparecida Bartholazzi de. Os italianos no noroeste Fluminense: estratégias familiares e mobilidade social 1897-1950. 2009. 285 f. Tese (Doutorado em História), Programa de Pós-Graduação em História da Universidade Federal Fluminense, Niterói.

CONSTANTINO, Núncia Santoro de. 0 italiano da esquina: meridionais na sociedade de Porto Alegre. Porto Alegre: EST, 2008.

CORTI, Paola. Identità e comunità d'origine nelle vechie e nelle nuove generazioni di emigranti: due paesi, due storie familiari. In: ROSOLI, G. et al. Identità e integrazione: Famiglie e paesi, percorsi e immagini di sè nell' emigrazione Biellese. Milano: Electa, 1990.

CIAFARDO, Eduardo. Cadenas migratorias e inmigración italiana. Reflexiones a partir de correspondencia dos inmigrantes italianos en Argentina, 1921-1938. Studi Emigrazione, v.XXVIII, 102, p. 233-255, 1991.

$\mathrm{CROCl}$, Federico. As cartas de chamada: vestígios das redes sociais e familiares transnacionais. In: CARNEIRO, Maria Luiz Tucci; CROCI, Federico; FRANZINA, Emilio (a cura di). História do trabalho e histórias da imigração: trabalhadores italianos e sindicatos no Brasil (séculos XIX e XX). São Paulo: Edusp: Fapesp, p. 299-321, 2010.

DA ORDEN, María. Liderazgo étnico, relaciones personales y participación política: los espanõles de Mar del Plata, 1883-1930. In: BJERG, María; OTERO, Hernán (Comp.). Inmigración y redes sociales en la Argentina moderna. Tandil: CEMLA- IEHS, 1995, p. 133168.

DEVOTO, Fernando. Las cadenas migratórias italianas: algumas reflexiones a la luz del caso argentino. Studi Emigrazione, v. XXIV, n.87, p. 355-373, 1988.

DEVOTO, Fernando. Le migrazioni italiane in Argentina: un saggio interpretativo. Napoli: L'Officina Tipografica, 1994. 
FRANZINA, Emilio. Merica! Merica! emigrazione e colonizzazione nelle lettere dei contadini Veneti in America Latina 1876-1902. Milano: Fertrinelli, 1979.

GIBELLI, Antonio. Fatemi un po sapere...: scrittura e fotografia nella corrispondenza degli emigrane liguri. In: GIBELLI, Antonio (a cura di). La via delle Americhe: I' emigrazione ligure tra evento e racconto - catalogo della mostra. Genova: Sagep Editrice, 1989.

GANDOLFO, R. Notas sobre la élite de uma comunidad emigrada en cadena: El caso de los agnoneses. In: DEVOTO, F. J; ROSOLI, G. F. (a cura di). L' Itália nella società argentina. Contributi sull'emigrazione italiana in Argentina. Roma, Centro Studi Emigrazione, p. 160-177, 1988.

GINZBURG, Carlo. O queijo e os vermes: o cotidiano e as ideias de um moleiro perseguido pela Inquisição. São Paulo: Companhia das Letras, 1987.

GINZBURG, Carlo. Os andarilhos do bem: feitiçarias e cultos agrários nos séculos XVI e XVII. São Paulo: Companhia das Letras, 1988.

GINZBURG, Carlo. O nome e o como: troca desigual e mercado historiográfico. In: GINZBURG, Carlo; PONI, Carlo; CASTELNUOVO, Enrico. A Micro-História e outros ensaios. Tradução de António Narino. Lisboa: DIFEL, 1989b.

GINZBURG, Carlo. O fio e os rastros: verdadeiro, falso e fictício. São Paulo: Companhia das Letras, 2007.

GINZBURG, Carlo. Mitos, emblemas e sinais. $2^{\text {a }}$ ed. São Paulo: Companhia das Letras, 2011.

GRENDI, Edoardo. Microanalisi e storia sociale. In: Quaderni Storici, n 35, 1977, p. 506520.

GRENDI, Edoardo. Polanyi: dall' antropologia economica alla microanalise storica. Milão: Etas libri, 1978.

GRENDI, Edoardo. O sistema político di una comunità lígure: Cervo fra cinquecento e seicento. Quaderni Storici, nº 46, p. 92-129, .apr., 1981,

GRENDI, Edoardo. II Cervo e la republica: il modello ligure di antico regime. Torino: Giulio Einaudi Editore, 1993.

GRENDI, Edoardo. Storia di uma storia locale: I' esperienza lìgure 1792-1992. Venezia: Marsilio Editori, 1996. 
LEVI, Giovanni. Centro e periferia di uno stato assoluto: tre saggi su Piemonte e Liguria in etá moderna. Turin: Rosemberg \& Seller, 1985.

LEVI, Giovani; RAMELLA, Franco. Immigrazione e doppio lavoro lungo il corso della vita: alcune osservazioni sul Piemonte dell'ottocento. Annali Alcide Cervi, 11, 1989, p. 88-101.

LEVI, Giovanni. A herança imaterial: trajetória de um exorcista no Pienonte do século XVII. Rio de Janeiro: Civilização Brasileira, 2000.

LEVI, Giovanni. Micro-história e história da imigração. In: VENDRAME, Maíra et. al. (Orgs.). Micro-história, trajetórias e imigração. São Leopoldo: Editora OIKOS, 2015, p. 246-262.

LEVI, Giovanni. 30 anos depois: repensando a Micro-História. In: VENDRAME, Maíra Ines; KARSBURG, Alexandre; MOREIRA, Paulo Roberto Staudt (Orgs.). Ensaios de MicroHistória, trajetórias e imigração. São Leopoldo: OIKOS, 2016a, p. 18-31.

LEVI, Giovanni. História Total versus Global History: a historiografia antes e depois da queda do Muro de Berlin. In: VENDRAME, Maíra; KARSBURG, Alexandre; MOREIRA, Paulo Staudt. Ensaios de micro-história, trajetórias e imigração. São Leopoldo: OIKOS; Editora Unisinos, 2016b, p. 72-85.

LIMA, Henrique Espada. A micro-história italiana: escalas, indícios e singularidade. Rio de Janeiro: Civilização Brasileira, 2006.

MAcDONALD, J. S; L. D. MACDONALD. Chain Migration, Ethnic Neighborhood and Social Networs. The Milbank Memorial Fun Quaterly, v. XLII, n.1, p. 82-96, 1964.

MARQUIEGUI, Dedier N. Migración em cadena, redes sociales y movilidad. Reflexiones a partir de los casos de los Sorianos y Albaneses de Luján, 1889-1920. In: BJERG, María; OTERO, Hernán (compiladores). Inmigración y redes sociales en la Argentina moderna. Tandil: CEMLA- IEHS, 1995, p. 35-60.

MARQUIEGUI, Dedier N. ¿Existió la microhistoria?. História Unisinos, São Leopoldo, v. 20, n.3, p. 249-259, Set./Dez. 2016. Disponivel em: <http://revistas.unisinos.br/index.php/historia/article/view/htu.2016.203.02/5735 >. Acessado 12 de junho de 2017.

OTERO, Hernán. Redes sociales primarias, mobilidade espacial e inserción social de los inmigrantes en Argentina. Los franceses de Tandil, 1850-1914. In: BJERG, María; OTERO, Hernán (Comp.). Inmigración y redes sociales en la Argentina moderna. Tandil: CEMLAIEHS, 1995, p. 81-106.

PEREIRA, Syrléa Marques. Entre histórias, fotografias e objetos: imigração italiana e 
memórias de mulheres. Niterói: Universidade Federal Fluminense, Departamento de História, 2008.

RAMELLA, Franco. Mobilidad geográfica y mobilidad social. Notas sobre la emigración rural de la Itália del Noroeste (1880-1914). Estudios Migratórios Latinoamericanos, v.6, n.17, p. 107-118, 1991.

RAMELLA, Franco. Por um uso flerte del concepto de red em los estúdios migratórios. In: BJERG, María; OTERO, Hernán (Comp.). Inmigración y redes sociales en la Argentina moderna. Tandil: CEMLA- IEHS, 1995, p. 9-22.

RAMELLA, Franco. Reti sociali, famiglia e strategie migratorie. In: BEVILACQUA, Piero; DE CLEMENTI, Andreina; FRANZINA, Emilio. Storia dell'emigrazione italiana: partenze. Roma: Donzelli Editore, 2001, p. 143-160.

RAMELLA, Franco. Gli studi sull' emigrazione tra vecchi paradigmi e nuove prospettive. In: SAIJA, M. (a cura di) L' emigrazione italiana transoceânica tra Otto e novecento e la storia delle comunitá derivate. Atti del Covegno Internazionale di Studi. Salina 1-6, guigno 1999. V. I - II. Messina: Edizione TRISFORM, 2003, p. 25-34.

SCOTT, Ana Sílvia Volpi. Entre idas e vindas: a contribuição da Micro-História para o estudo da migração entre Portugal e Brasil. In: VENDRAME, Maíra; KARSBURG, Alexandre; MOREIRA, Paulo Staudt. Ensaios de micro-história: trajetória e imigração. São Leopoldo: OIKOS; Editora Unisinos, 2016, p. 211-268.

STURINO, F. Emigracion italiana: reconsideracion de los eslabones de la cadena migratória. In: Estudos Migratórios Latinoamericanos, v.3, n.8, p. 5-25. 1988.

VENDRAME, Maíra Ines et. al. (Orgs.). Micro-história, trajetórias e imigração. São Leopoldo: Editora OIKOS, 2015a.

VENDRAME, Maíra Ines et. al. (Orgs.).Mobilidade, redes e experiências migratórias: reflexões sobre as estrátegias de transferência dos imigrantes italianos pra o Brasil meridional. In: VENDRAME, Maíra et. al. (Orgs.). Micro-história, trajetórias e imigração. São Leopoldo: Editora OIKOS, 2015b, p. 200-223.

VENDRAME, Maíra Ines. O poder na aldeia: redes sociais, honra familiar e práticas de justiça entre os camponeses italianos (Brasil/Itália). São Leopoldo: Editora Oikos, 2016a.

VENDRAME, Maíra Ines; KARSBURG, Alexandre; MOREIRA, Paulo Staudt (Org.). Ensaios de micro-história, trajetórias e imigração. São Leopoldo: OIKOS; Editora Unisinos, 2016b. 
VENDRAME, Maíra Ines. "Com tinta do meu sangue": redes e mobilidades através das cartas de um imigrante italiano. In: BENEDUZZI, Fernando; DADALTO, Maria Cristina. Mobilidade humana e circularidade de ideia: dialógos entre América Latina e Europa. Venezia: Edizioni Ca’Foscari - Digital Publishig, 2017a, p. 67-78. (E-book disponível em: <http://edizionicafoscari.unive.it/media/pdf/chapter/978-88-6969-123-2/978-88-6969-123-2ch-05.pdf $\geq$. Acessado 12 de junho de 2017.

VENDRAME, Maíra Ines. "Em busca da República de Deus”: revoltas camponesas e agentes de emigração no norte italiano (século XIX). Revista Tempo, V.23, n.1, Jan./Abr., p. 23-42, 2017, Disponível em, <http://www.scielo.br/pdf/tem/v23n1/1980-542X-tem-23-0100022.pdf $\geq$. Acessado 19 de junho de 2017b.

Recebido em 29/07/2017

Aprovado em 11/11/2017

Universidade do Estado de Santa Catarina - UDESC

Programa de Pós-Graduação em História - PPGH

Revista Tempo e Argumento Volume 10 - Número 25 - Ano 2018 tempoeargumento@gmail.com 